\title{
Improvement of rural development system through interaction with penitentiary institutions
}

\author{
Olga Olesiyuk ${ }^{1, *}$, Ildar Fazliyev ${ }^{2}$, and Andrey Svetlakov ${ }^{1}$ \\ ${ }^{1}$ Federal State Budgetary Educational Institution of Higher Education "Perm State Agrarian - \\ Technological University named after academician D.N. Pryanishnikov", Krasnoflotskaya st., 11, \\ Perm \\ ${ }^{2}$ Federal State Budgetary Educational Institution of Higher Education "Perm State National Research \\ University"
}

\begin{abstract}
The article is devoted to the identification of ways to solve socioeconomic problems of rural territories and territorial formations on which penitentiary system institutions are located. The authors provide an analysis of rural territories of Perm Krai and reveal the results of demographic processes and accompanying causal relations. The possibility of solving employment problems of previously convicted people and repleshiment of labor resources shortage by this was offered. The mutual benefit of such cooperation was demonstrated for the administrations of these institutions and municipalities, expressed in increasing the economic potential of institutions and territories and reducing social tensions in these territories in the process of solving socio - economic contradictions. The need to assess the institutions" economic potential and the level of social tension was established. The considered problem's relevance for any rural territory of our country where the penitentiary system institutions are located makes the authors-proposed approach interesting from the practical application point of view to specialists in the field of state and municipal administration, agriculture in economic development as federal bodies, public authorities, subjects of the Russian Federation and local governments.
\end{abstract}

\section{Introduction}

The current situation in the economy is generally characterized by stagnation caused by "Western sanctions" and the COVID-19 pandemic; it has led to the understanding of the need to develop agriculture as an essential element not only of food, but also social and economic security.

At the same time, Russian President V. Putin is confident that: "Not only can we feed ourselves, but also, given our land and water resources, which is especially important, Russia is able to become the world's largest supplier of healthy, environmentally friendly, highquality food products that have been long gone at some Western producers, especially since the demand for such products on the global market is steadily growing» [1].

\footnotetext{
${ }^{*}$ Corresponding author: olesiuk@yandex.ru
} 
In our opinion, the agricultural sectors' subsidiary farms of the Federal Penitentiary Service institutions (hereinafter referred to as the FPS) can make a significant (sizeable, serious) contribution to this since they have a certain resource.

More detailed consideration of the mentioned topic will be given based on the condition analysis of rural territories and subsidiary farms in the FPS institutions of Perm Krai.

\section{Materials and methods}

Analytical, statistical and monographic methods of research were used in the presented paper. The information basis of the research was the statistical data of the Federal Penal Service of the Russian Federation and the Federal State Statistics Service and its territorial organ in Perm Krai.

\section{Results and discussion}

Today in the rural areas of Perm Krai as in general in Russia, there is a steady negative trend in the social and economic development of these territories mainly conditioned by demographic problems, namely the depopulation and ageing of the population, and secondly - the decline in the standard and quality of life of the rural population.

It should be noted that in modern realities, the quality of life of the population is one of the main principles of progress, so high economic indicators do not always determine the successful development of territories, but rather means of achieving high quality of life [2].

Thus, over the past ten years, the rural areas population of the Kama region has decreased by 41.6 thousand people from 667,9 thousand people in 2010 to 626,3 thousand in 2019 . During this period, the share of rural population in the total population structure of the region also decreased by $1.1 \%$ from $25.2 \%$ to $24.1 \%$.

The number of deaths prevails over the number of births: if in 2010 in rural areas there were 11,219 people born and 11,876 dead with the natural decrease of 657 people, then in 2019 there were 6,800 born, 9,244 dead with the natural decease of 2,444 [3]. The negative trend in the natural movement of the rural population of Perm Krai over the last 10 years is shown in Figure 1.

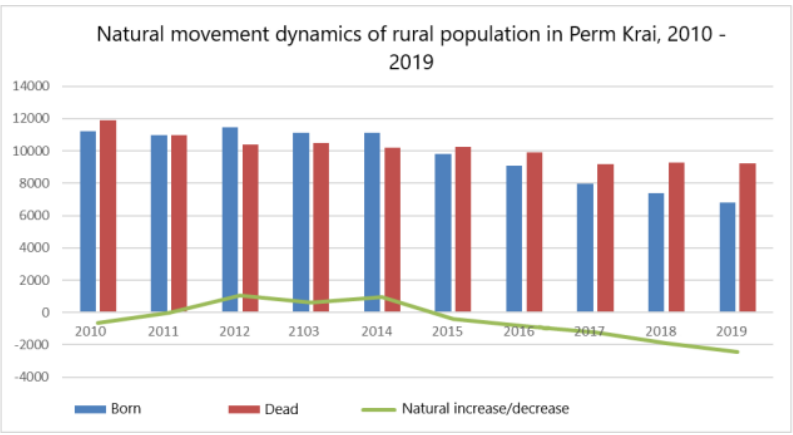

Fig. 1. Dynamics of the natural movement of rural population of Perm Krai for $2010-2019$.

Source: composed by the authors.

Migration outflow of the rural population has more than quadrupled during this period (in 2010 - 509 people, in 2019 - 2263 people), which is shown in Figure 2.

First to migrate is the young population of working age, i.e. economically active population that makes up the labor resource of the village. In general, it should be noted that 
the abovementioned phenomena are a consequence of the population's reaction to both political and economic and social processes taking place in society.

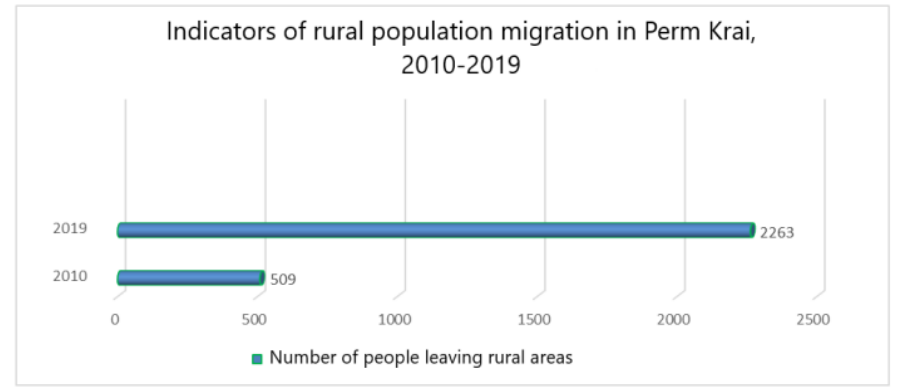

Fig. 2. Migration rates of rural population of Perm Krai in 2010 and 2019.

Source: composed by the authors.

As a consequence, the population above the working age exceeds the working-age population (632), and their trends are marked by polarity: the first in the period from 2011 to 2019 years increased by 48 thousand people from 583,8 thousand in 2011 to 632,2 thousand in 2019 , the second, on the contrary, decreased by 140 thousand people from 1577,8 thousand people to 1438,1 [3].

Thus, the ageing of the population is at an almost triple outpacing rate.

Unemployment in rural areas remains a serious problem, which despite a decrease of $7.3 \%$ since $2010(40.3 \%$ in $2010,33.0 \%$ in 2019$)$ remains quite high in the overall structure of registered unemployed people in the region [3].

If we talk about the average monthly nominal accrued wage in agriculture, hunting and forestry, its gap compared to the average of the region although tends to decrease, but remains quite serious: in 2010, the average monthly nominal accrued salary in agriculture, hunting and forestry was 8543.1 rubles, in the region - 17438.3 rubles, which is less than twice, in 2019 - 23225 rubles and 39209,9 rubles respectively with the difference by 1.7 times [3].

The low level of material security together with the peculiarities of a person's world view and upbringing provides a favorable ground for his asocial behavior, even in illegal ways [4].

It is also impossible to say that the living conditions in the countryside are close to those of the city in terms of living comfort and provision of social and engineering infrastructures, because during the period under study their dynamics had a negative character: the number of kindergartens decreased by 1.9 times (in 2010 there were 608, in 2019 - 326), schools - 1.5 times (in 2010 there were 492, in 2019 - 333), libraries - by 1.8 times (from 621 in 2010 to 352 in 2019), cultural and leisure organizations - 1.2 times $(2010-781,2019-$ 646), introduced gas networks - 2.7 times less (in $2010-219.6 \mathrm{~km}$, in $2019-79.9$ ), and water networks and power lines were not introduced at all in 2019 (in 2010 they amounted to $23.6 \mathrm{~km}$ and $165.5 \mathrm{~km}$ respectively) [3].

Based on this analysis, it can be stated that today there is an alarming socio-economic situation characterized by the above indicators in the rural territories of Perm Krai.

At the same time, solving the problem of employment in rural areas can be viewed from the point of view of interaction with the penitentiary institutions, which will have a synergistic effect.

There are 28 institutions of the FPS system in rural areas of Perm Krai [5]. The vast number of these institutions are located outside urban areas and have agricultural subsidiary farms in their structure. The activities of such institutions are also accompanied by a number of contradictions. On the one hand, there are resources, particularly labor, to perform work that does not require high qualifications and specific knowledge. On the other hand, these institutions have a lack of specialists in agricultural areas (agronomists, zootechnics, etc.) - 
they are not certified employees, their salaries are therefore not high, but such staff "supervise" several institutions.

In addition, due to current legislation, FPS institutions are not agricultural producers, so they cannot benefit from state assistance in the form of subsidies, grants, and subventions.

At the same time, the economic potential of FPS institutions was determined by the authors earlier, where the formula for its calculation was given:

$\mathrm{EP}=(\mathrm{MR}+\mathrm{HR}+\mathrm{FR}+\mathrm{AR}+\mathrm{IR}) / 100=1$,

where EPs include the following nominal indicators:

MR - material resources - includes capital (buildings, land, equipment, etc.) - 35\%

HR - human resources - includes special squads and institution's specialists - 30\%

FR - financial resources - funds - 20\%

$\mathrm{AR}$ - administrative resources that constitute management and control functions $-10 \%$

IR - intangible resources - includes innovative technologies, intangibles (list of information) $-5 \%$.

Moreover, this formula is universal and applicable in all industries, including agriculture.

With specific indicators out of the abovementioned, it is possible to obtain other figures, but not more than one: 0.9 and above is the maximum level of economic potential, the lowest up to 0.1 is the indicator reflecting the negative result of economic potential management [6].

The role of agriculture in the economy of a particular locality, region and country as a whole is inestimable, so this branch of economy will always be in demand regardless of geoeconomic and geopolitical processes. In this regard, the industry needs close attention from the authorities at all levels.

This formula for calculating economic potential will allow to assess the potential of both FPS institutions located on a specific rural territory and enterprises located in this territory.

If an agricultural enterprise is located in a rural area, in order to increase its production it is possible to attract employees not requiring high qualifications and qualifications in general from among the special squads of the FPS institution. Thus, it is possible to solve the problem of the labor shortage, which is currently being addressed by migrant workers from the "near abroad" countries, and today is of special importance due to the restrictions imposed in order to prevent the spread of the new coronavirus infection on entry into the country [7].

On the other hand, if the FPS institution has an agricultural subsidiary farm, it is possible to attract specialists from the number of living rural population for its production increase.

It should be noted that at present, the issue of convicts' employment is receiving increasing attention, but currently not all convicts are provided with work. This entails negative consequences both in the process of correction itself and the inability to purchase products and goods for personal consumption, as well as the deprivation of material support for their families and compensation for the harm caused by the crime in the claims. In addition, lack of work and subsequent earnings deprives convicts from forming funds in personal accounts and constitutes a serious barrier to their further - after serving their sentences - painless and rapid adaptation in society [9].

When considering this problem, it is possible to implement the idea put forward by Malinin V.B., which is to shift the paradigm of punishment: to consider it not as a torment, but as a compensation process for damage to the individual or society [9].

Penitentiary labor should not be a measure of increasing punishment, but as a means of ensuring the re-adaptation of the prisoner, which should give skills in a craft and impart a labor habit. The labor of a convicted prisoner should be as close to free labor as possible. Prisoners should be paid in accordance with their work, the amount of which should be so that they can provide material assistance to his/her family, if necessary. [10]

In practice, the wages of convicts are meagre, many times less than the minimum [11].

To solve this problem, employment of convicts in agricultural subjects seems promising: in this case, the task of providing them with work and an adequate salary would be solved. 
Moreover, a good motivation for such employers would be, for example, the system of tax benefits.

Such a mechanism of joint work fits into the legal framework of our country - in particular, part 3.1 of Article 129 of the Criminal and Executive Code of the Russian Federation and the order of the FPS of Russia dated December 18, 2019 No.1160, which approved a model contract between a penal settlement and an organization employing convicted labor in a settlement site located outside the territory of the penal settlement [12, 13].

Thus, the interaction of the local administration and the institution's administration will lead to mutual benefits: employment of the population and the special squads, increase in labor productivity and consequent population's income, which will have a positive impact on the social and economic development of the territory and will lead to social tensions' leveling of its population.

To prevent the occurrence of social tension, it is also necessary to assess its level in order to identify signs of emerging phenomena in a timely manner and take measures to eliminate them promptly.

\section{Conclusion}

The following results were obtained as a result of the study:

The study showed that today the development of rural areas is hindered by several demographic and socio-economic problems, which are aggravated by the increasing urbanization of society.

These problems can be solved using the labor resource of penitentiary institutions.

It is necessary to develop production in FPS institutions, look for ways to improve their profitability and self-sufficiency, find opportunities for compensating the damages from crimes and repayment of alimony obligations of convicts, as well as their own savings of earned money for social adaptation upon release.

The proposed interaction mechanism between territories' administrations and FPS institutions will lead to a synergistic development result of both rural areas and subsidiary farms of these institutions.

To develop competent management decisions, it is necessary to use the developed method of assessing the economic potential of the institution, and to assess its level considering innovative methodological tools for preventing or leveling social tensions.

In order to obtain a socio-economic effect, the analysis and development of adequate measures should possess a systemic and integrated approach, then the instructions of the head of our state can be implemented to life and lead to the set goal of the rural territories' development as a guarantor of the state security.

\section{References}

1. V.V. Putin, President's Message to the Federal Assembly, http://www.kremlin.ru

2. A.G. Svetlakov, I. M. Glotina, Regional economy, 14(2), 474 (2018)

3. Territorial body of the Federal Service of State Statistics in Perm Krai, http://permstat.gks.ru/

4. A.V. Gurnitsky, Society and Law, 1(51), 174 (2015)

5. GUFSIN of Russia in Perm Krai, https://59.fsin.gov.ru

6. I.N. Fazliev, A.G. Svetlakov, Formation and management of subsidiary farms development in special FPS system institutions, 201 (2018) 
7. Ministry of Agriculture of the Russian Federation, https://mcx.gov.ru

8. S. V. Garnik, V. A. Kazakova, Man: Crime and Punishment, 26(1-4), 76 (2018)

9. V. B. Malinin, IX Russian Congress of Criminal Law on May 29-30, 334 (2014)

10. Proceedings of the first UN Congress on the prevention of crime and handling of offenders, 1 (1958) http://www.consultant.ru

11. A.I. Drozdov, Bulletin of the Kuzbass Institute, 4(29) (2016)

12. Penal Code of the Russian Federation, http://www.consultant.ru

13. Order of the FPS of Russia dated December 18, 1160 (2019), http://www.consultant.ru 